REVIEW

\title{
The heart and the oesophagus: intimate relations
}

\author{
M Heatley, K Rose, C Weston
}

Postgrad Med J 2005;81:515-518. doi: 10.1136/pgmj.2004.029074

The close anatomical relations of the heart and oesophagus, and the similarity of symptoms attributable to disorders of either organ, often lead to diagnostic difficulty in patients with chest pain. A definitive diagnosis of noncardiac chest pain attributable to oesophageal reflux or spasm is hampered, both by the need for prolonged ambulatory monitoring of $\mathrm{pH}$, manometry, and endoscopy, and by the common occurrence of asymptomatic reflux and spasm, and the corresponding difficulty in linking an episode of reflux or spasm with an episode of pain. Moreover, some patients with non-cardiac chest pain and normal tests of oesophageal structure and function have centrally mediated hypersensitivity, both within and without the oesophagus. Rather than proceed with investigations, in the absence of symptoms to suggest structural disease of the oesophagus, it would be reasonable to attempt symptomatic treatment with a proton pump inhibitor or an antidepressant.

See end of article for authors' affiliations

Correspondence to: Dr C Weston, Department of Cardiology, Singleton Hospital, Swansea, Wales SA2 8QA; cfmw@lycos. com

Submitted

24 September 2004

Accepted

18 December 2004
$\mathrm{T}$ he relation between the heart and the oesophagus within the mediastinum, with the oesophagus being posterior to, and separated from the left atrium by, the pericardium, is used to advantage by cardiologists during transoesophageal echocardiographic examinations. However, the same relation, and in particular the common path of pain fibres from both organs via the sympathetic trunk, leads to one of the commonest dilemmas facing clinical cardiologists-the correct diagnosis of patients with chest pain. Chest pain is a common complaint and cardiac and oesophageal pains are often similar. It is taught that the characteristic pain of oesophageal reflux is burning in nature, epigastric in origin, and related to recent food, bending, or lying down, and that of oesophageal spasm is retrosternal, deep rather than superficial, and described as burning, squeezing or aching, radiating to the arms, jaw, and back. Certain extra-oesophageal symptoms may be associated with gastro-oesophageal reflux, leading to presentation to respiratory physicians (with cough and wheeze) and ear, nose, and throat specialists (with hoarseness and laryngitis. ${ }^{1}$ Although often related to meals, oesophageal chest pain can also be precipitated by emotion and exercise-qualities that mimic the symptoms of angina pectoris attributable to ischaemic heart disease (IHD). Furthermore, a number of the risk factors for the development of coronary disease, such as cigarette smoking, obesity, and diabetes, also increase the likelihood of oesophageal disorders, and medical treatments of angina often have beneficial effects on oesophageal symptoms.

Patients with chest pain may therefore be subjected to a battery of tests, usually initially intended to seek objective evidence of ischaemia attributable to coronary artery disease and when this is excluded to look for other treatable causes. In this article we use the literature to illustrate the link between oesophageal and cardiac function, and to determine an appropriate management once IHD is excluded and oesophageal disorder is felt probable.

\section{THE CARDIO-OESOPHAGEAL REFLEX}

Cardiac enlargement can cause extrinsic oesophageal compression, for example, both left atrial dilatation attributable to chronic rheumatic mitral stenosis and postoperative pericardial effusion have been reported as presenting with dysphagia. $^{2}$ Moreover, compression of the left atrium by a huge hiatus hernia has been reported as an unusual cause of syncope. ${ }^{3}$ Other than these direct mechanical effects, a neural reflex, mediated by the vagus nerve, exists that allows changes in oesophageal function to affect cardiac physiology. "Swallow syncope" or "deglutition syncope" - changed consciousness triggered by the act of swallowing-associated with complete heart block or sinus arrest, has been well described. In fact bradycardia occurs in most people during balloon inflation within the oesophagus. It is started by afferent stimulation of mechanoreceptors in the lower oesophagus and the efferent fibres may be blocked by atropine. ${ }^{4}$ Atrial tachycardias can also be triggered by swallowing and belching, although the precise neural mechanism remains uncertain. ${ }^{5}$

It has been suggested that oesophageal dysfunction could itself trigger myocardial ischaemia- "linked angina". ${ }^{6}$ Support for this view comes from the associated reduction in coronary artery blood flow velocity, measured during intracoronary duplex studies, that accompanies the instillation of acid into the oesophagus. This is seen regardless of the presence or absence of epicardial coronary artery disease, but is absent in the denervated hearts of heart transplant recipients; again confirming the presence of a "cardio-oesophageal reflex". ${ }^{7}$ Taken further, this leads on to the possibility that the pain of myocardial ischaemia could be started by reduced coronary flow, secondary to oesophageal acid reflux. While this may seem feasible if the reduction in coronary blood flow occurred in the

Abbreviations: IHD, ischaemic heart dieseae; NCCP, non-cardiac chest pain 
presence of critical atheromatous coronary disease, a similar mechanism seems unlikely to account for myocardial ischaemia in the presence of angiographically normal arteries, unless macrovascular coronary spasm is induced. Pain attributable to oesophageal disorders is more likely to be sensed directly via oesophageal chemosensitive and mechanosensitive nociceptors in response to changes in $\mathrm{pH}$ (reflux) or pressure (spasm) respectively. ${ }^{8}$

\section{NON-CARDIAC CHEST PAIN}

As mentioned above, confirming the diagnosis of IHD is difficult. Commonly used exercise testing protocols, for instance, have a sensitivity and specificity of $68 \%$ and $77 \%$ respectively.' Many cardiologists resort to coronary angiography when there is any doubt. When coronary arteries appear normal on angiography, particularly when there is no other cardiac disorder (for example, aortic stenosis) or objective evidence of ischaemia, a diagnosis of non-cardiac chest pain (NCCP) is made. The outlook for this group seems to be good in terms of mortality risk, but poor in terms of control of symptoms. Patients found to have normal coronary arteries have a cardiac mortality of $0.09 \%$ per year and a coronary event rate of $0.65 \%$ per year but persisting chest pain in $81 \%$ over nine year follow up. ${ }^{10}$

Of course, the revelation of coronary disease by angiography does not necessarily mean that all episodes of chest pain in that patient are of cardiac origin. The clinician often is faced with the problem of a patient with comparatively mild coronary disease but persisting severe symptoms despite antianginal drugs. It is probable that many of these patients have coexisting coronary disease and symptomatic oesophageal disorder. ${ }^{11}$ It is important that those involved in the management of patients with chest pain should have some understanding of the management of oesophageal pain. Simply stating that the pain is "non-cardiac" or "atypical" may not be good enough. In our experience, patients with chest pain require a "cause" or explanation for their symptoms.

\section{OESOPHAGEAL REFLUX}

Intraoesophageal acid perfusion (Bernstein test) was described as a provocation test in 1958. It is not now widely used. Such provocation tests cause far greater decreases in $\mathrm{pH}$ than physiological (spontaneous) acid reflux. However, they confirm that acid in the lower oesophagus causes chest pain, that stronger acid infusions are more likely to cause pain, ${ }^{12}$ that repeated infusions reproduce that pain and that shorter intervals between repeat infusions are associated with more rapid return of pain..$^{13}$ Acid perfusion reduces the threshold to pain induced by subsequent oesophageal balloon inflation, ${ }^{14}$ and is associated with a sensitising of the lower oesophagus to painful stimuli that persists beyond the duration of infusion, and may also affect the upper oesophagus (above the zone affected directly by the lowered $\mathrm{pH}^{15}$

Furthermore, in those with coronary disease, acid provocation studies may induce pain that is indistinguishable from angina. ${ }^{16}$ In some studies up to a third of patients have ST segment changes during acid infusion, supporting the importance of the cardio-oesophageal reflex (see above). This is not a consistent finding. Oesophageal acid infusion during exercise testing in coronary patients, has been associated with a shorter duration of exercise required to induce typical symptoms, without affecting the timing or intensity of electrocardiographic changes. ${ }^{17}$

Although upper gastrointestinal endoscopy may show macroscopic or microscopic abnormalities related to oesophageal reflux, 24 hour ambulatory $\mathrm{pH}$ monitoring has become the investigation of choice for showing physiological reflux, and attempting to link the occurrence of reflux with daily activities, exercise testing, and with symptoms. This linkage is difficult to achieve. Just as in the case of ST segment depression in those with coronary disease-occurring more often than symptoms predict—reflux is common in patients with NCCP and may be asymptomatic, and not consistently linked to episodes of pain. Most symptomatic periods seem to be the culmination of a series of episodes of reflux, again suggesting a sensitising effect. ${ }^{18}$ Generally, ambulatory monitoring has failed to show pathological ST segment depression in association with physiological reflux, and reflux is as likely to occur before, during, or after exercise testing and is not associated with ST changes in those with normal coronary arteries. ${ }^{19}$

However, in a more select group of patients admitted to a cardiac care unit because of retrosternal chest pain, yet soon thought unlikely to be suffering acute myocardial infarction, continuous oesophageal monitoring was started (on average) 62 minutes after admission. Of these, 14 of 30 (47\%) had evidence of reflux, 12 of $30(40 \%)$ motility disorders (see below), one both, and three neither abnormality; 27 of $30(90 \%)$ experiencing pain had related oesophageal abnormalities. ${ }^{20}$

Reflux seems no more common in patients with NCCP than in those with coronary disease, ${ }^{21}$ and has been shown to play a part, as expected, in the symptoms of those with reported coronary disease. In one study of patients with coronary disease, 20 of 31 patients experienced 53 episodes of chest pain during oesophageal monitoring. There were many asymptomatic episodes of reflux, but 37 of the episodes were preceded within 10 minutes by reflux. Only seven episodes of pain were associated with ST segment change, two of which were preceded by reflux. ${ }^{22}$

A British primary care study of adults with a new diagnosis of gastro-oesophageal reflux disorder showed a relative risk of later myocardial infarction of 1.4 (95\% confidence interval 1.0 to 1.9) over a mean follow up of 27 months, when compared with age matched controls. The increased risk was limited to the immediate days after the diagnosis was made, and probably reflects a misinterpretation of the presenting symptoms rather than the triggering of myocardial infarction by reflux. ${ }^{23}$

\section{OESOPHAGEAL SPASM}

Abnormalities in pressure developed within the oesophageal lumen are common, with "non-specific oesophageal motor disorder", nutcracker oesophagus (generally being defined as episodes of pressure $>180 \mathrm{~mm} \mathrm{Hg}$ ), diffuse oesophageal spasm, and both low and high lower-oesophageal sphincter tone being generally the commonest reported. Once again, there seems to be little difference in the prevalence of dysmotility between those with NCCP and those with coronary disease, although both have more motility problems than controls. ${ }^{24}$

"Stationary" motility abnormalities are reported in between $28 \%$ and $63 \%$ of those with NCCP. However, a temporal link between the spasm and the pain is the exception, in fact one study suggested that episodes of spasm were just as likely to occur after as before an episode of chest pain. ${ }^{25}$ Furthermore, the reproducibility of such tests is poor, and agreement with the findings of ambulatory oesophageal manometry is not great. A study using endoscopic ultrasonography showed episodes of sustained isometric contraction of circular smooth muscle fibres within the oesophagus during chest pain. This was not associated with luminal constriction, nor with longitudinal muscle fibre contraction, and was not therefore recorded manometrically. ${ }^{26}$ This may go some way towards explaining the poor utility of manometry. 
Generally the "diagnostic yield" seems to improve using ambulatory manometry, with, in one study, $48 \%$ of pains correlating with motility abnormalities. ${ }^{27}$ However, others have reported no differences in 24 hour oesophageal motility between NCCP patients and controls, and in a study of 90 patients experiencing 144 episodes of pain during ambulatory manometry, only four episodes were thought to be related to spasm; there was little gain from ambulatory monitoring. ${ }^{28}$

\section{TRIAL OF TREATMENT}

Despite investigations an obvious cause of chest discomfort is often not found. One study of 87 patients who underwent extensive testing including coronary flow reserve estimation during rapid atrial pacing, before and after ergonovine and dipyridamole intravenously, then within the same week oesophageal motility, Bernstein testing, and oesophageal balloon dilatation, concluded that it was impossible to determine a distinct cause for pain in $85 \% .^{29}$

Faced with a patient with NCCP, or with a patient with coronary disease and probable coexisting oesophageal disorder, should the clinician arrange invasive investigations of the oesophagus? In the absence of dysphagia, or other signs/ symptoms to suggest a structural defect, it has been suggested that prescription of a proton pump inhibitor can be used "as a diagnostic test". A study using lansoprazole $30 \mathrm{mg}$ daily for four weeks has shown that a symptomatic improvement strongly predicts the presence of significant reflux; sensitivity $92 \%$, specificity $67 \%$, positive predictive value $58 \%$, negative predictive value $94 \% .^{30}$ Cost effectiveness analysis suggests that such an approach would result in a greater proportion of symptom free patients at one year, fewer tests, and cost savings compared with traditional strategies that begin with invasive diagnostic tests. As a result a trial of treatment with proton pump inhibitors has been recommended for patients with suspected reflux related oesophageal symptoms, with duration of the trial from one week $^{31}$ to four weeks ${ }^{32}$; only if symptoms fail to improve would further oesophageal investigations be organised. Of course, those that respond to this short term treatment are likely to require long term therapy, or repeated courses of treatment.

Nitrates may reduce lower oesophageal sphincter pressure ${ }^{33}$ and calcium channel blockers such as diltiazem lower the peristaltic pressure in nutcracker oesophagus. Small placebo controlled studies show symptomatic efficacy. ${ }^{34}$ So there are reasons why antianginal drugs could relieve the symptoms of oesophageal disorders, and this could lead to diagnostic confusion. Conversely, it has been suggested that treatment of angina with nitrates and calcium channel blockers may, through relaxation of the lower oesophageal sphincter, cause symptomatic reflux as a "side effect". ${ }^{35}$ In practice the response to drugs specifically aimed at dysmotility is disappointing.

\section{CENTRAL CHANGES}

There is a high prevalence of psychiatric disturbance in patients with NCCP. Compared with people with coronary disease, those with NCCP are more likely to have panic disorders (43\% compared with 6.5\%), major depression (36\% compared with $4 \%$ ), and multiple phobias (36\% compared with $15 \%),{ }^{36}$ and to have more intense autonomic symptoms (palpitation, dizziness, and parasthesia) during episodes of pain.

At the time of angiography, $61 \%$ of patients with chest pain and normal coronary arteries were shown to have psychiatric abnormalities (mostly anxiety), and this persisted in $49 \%$ of patients at 11.4 years' follow up. ${ }^{37}$ Psychological management, particularly cognitive behavioural therapy, may prove beneficial, but may also be rejected by less enthusiastic patients. $^{38}$ Treatment with tricyclic antidepressants has resulted in initial improvement in symptoms of chest pain in as many as $81 \%$, with a sustained response in $41 \%$ over an average of 2.6 years. ${ }^{39}$ Comparatively low doses of imipramine (50 mg daily) and trazadone (100-150 mg daily) have proved beneficial with respect to chest pain, although this symptomatic improvement has been seen without any manometric change $^{40}$ and, more importantly, without any measurable change in mood. ${ }^{41}$ This implies that these drugs are acting, not as central antidepressants or anxiolytics, but as pain desensitisers.

Experiments with oesophageal acid infusion have shown exaggerated and prolonged reductions in pain threshold in patients with NCCP. ${ }^{15}$ This hypersensitivity extends upwards to involve parts of the oesophagus that had not been in direct contact with acid. This may be a reflection of "central sensitisation" attributable to greater excitability of spinal cord neurons, secondary to increased activity of afferent nociceptive $C$ fibres upon dorsal horn cells. While six weeks of treatment with high dose proton pump inhibitors has been shown to increase the pain threshold in the upper oesophagus, ${ }^{42}$ such visceral hypersensitivity may be attenuated by drugs that antagonise central nervous system $N$-methyl-Daspartate receptors ${ }^{43}$ or the prostaglandin $\mathrm{E}_{2}$ receptor. ${ }^{44}$ This area of research holds the prospect of significant progress in managing these patients.

\section{SUMMARY}

Chest pain is a common symptom. When coronary arteries are found to be normal on coronary angiography, or where severe symptoms persist in the presence of mild coronary disease, it is probable that oesophageal disorders are involved. The definitive diagnosis of NCCP attributable to oesophageal disorder is hampered by the need for prolonged ambulatory monitoring of $\mathrm{pH}$ and manometry, the common occurrence of asymptomatic reflux and spasm, and the difficulty in linking an episode of reflux or spasm to an episode of pain. Rather than proceed with such investigations, in the absence of symptoms to suggest structural disease of the oesophagus, it would be reasonable to attempt a four week trial of high dose proton pump inhibitor, or, if psychiatric symptoms are present, low dose antidepressant therapy.

\section{ACKNOWLEDGEMENTS}

We thank the reviewers of the first draft of this paper for their constructive comments.

Authors' affiliations
M Heatley, K Rose, C Weston, Department of Cardiology, Singleton
Hospital, Swansea, Wales
Funding: none.
Competing interests: none.

\section{REFERENCES}

1 Jaspersen D. Extra-esophageal disorders in gastroesophageal reflux disease. Dig Dis 2004;22:115-19.

2 Bryan A, Weston C, Angelini G. Late postoperative cardiac tamponade presenting with dysphagia. Ann Thorac Surg 1989:47:922-3.

3 Maekawa T, Suematsu M, Shimada T, et al. Unusual swallow syncope caused by huge hiatal hernia. Intern Med 2002;41:199-201.

4 Kakuchi H, Sato N, Kawamura Y. Swallow syncope associated with complete atrioventricular block and vasovagal syncope. Heart 2000;83:702-4.

5 Wilmshurst PT. Tachyarrhythmias triggered by swallowing and belching. Heart 1999;81:313-15.

6 Smith KS, Papp C. Episodic, postural, and linked angina. BMJ 1962;iv:1425-30.

7 Chauhan A, Petch MC, Schofield PM. Cardio-oesophageal reflex in humans as a mechanism for "linked angina". Eur Heart J 1996;17:407-13.

8 Orlando RC. Esophageal perception and noncardiac pain. Gastroenterol Clin North Am 2004;33:25-33. 
9 Gianrossi R, Detrano R, Mulvihill D, et al. Exercise-induced ST depression in the diagnosis of coronary artery disease. A meta-analysis. Circulation 1989;80:87-98

10 Lichtlen PR, Bargheer K, Wenzlaff P. Long-term prognosis of patients with angina like chest pain and normal coronary angiographic findings. J Am Coll Cardiol 1995;25:1013-18.

11 Singh S, Richter JE, Hewson EG, et al. The contribution of gastroesophageal reflux to chest pain in patients with coronary artery disease. Ann Intern Med 1992;117:824-30.

12 Smith JL, Opekun AR, Larkai E, et al. Sensitivity of the esophageal mucosa to $\mathrm{pH}$ in gastroesophageal reflux disease. Gastroenterology 1989;96:683-9.

13 Siddiqui MA, Johnston BT, Leite LP, et al. Sensitization of esophageal mucosa by prior acid infusion: effect of decreasing intervals between infusions. Am J Gastroenterol 1996:91:1745-8.

14 Mehta AJ, De Caestecker JS, Camm AJ, et al. Sensitization to painful distention and abnormal sensory perception in the esophagus. Gastroenterology 1995; 108:31 1-19.

15 Sarkar S, Aziz Q, Woolf CJ, et al. Contribution of central sensitisation to the development of non-cardiac chest pain. Lancet 2000;356:1154-9.

16 Mellow MH, Simpson AG, Watt L, et al. Esophageal acid perfusion in coronary artery disease. Induction of myocardial ischemia. Gastroenterology 1983;85:306-12.

17 Davies HA, Page Z, Rush EM, et al. Oesophageal stimulation lowers exertional angina threshold. Lancet 1985;i:1011-14.

18 Beedassy A, Katz PO, Gruber A, et al. Prior sensitization of esophageal mucosa by acid reflux predisposes to reflux-induced chest pain. J Clin Gastroenterol 2000;31:121-4.

19 Cooke RA, Anggiansah A, Smeeton NC, et al. Gastroesophageal reflux in patients with angiographically normal coronary arteries: an uncommon cause of exertional chest pain. Br Heart J 1994;72:231-6.

20 Lam HG, Dekker W, Kan G, et al. Acute noncardiac chest pain in a coronary care unit. Evaluation by 24 -hour pressure and $\mathrm{pH}$ recording of the esophagus. Gastroenterology 1992;102:453-60.

21 Cooke RA, Anggiansah A, Chambers JB, et al. A prospective study of oesophageal function in patients with normal coronary angiograms and controls with angina. Gut 1998;42:323-9.

22 Garcia-Pulido J, Patel PH, Hunter WC, et al. Esophageal contribution to chest pain in patients with coronary artery disease. Chest 1990;98:806-10.

23 Johansson S, Wallander M-A, Ruigomez A, et al. Is there any association between myocardial infarction, gastro-oesophageal reflux disease and acidsuppressing drugs? Aliment Pharmacol Ther 2003;18:973-8.

24 Adamek RJ, Roth B, Zymanski CH, et al. Esophageal motility patterns in patients with and without coronary heart disease and healthy controls. Hepatogastroenterology 1999;46:1759-64.

25 Lam HG, Breumelhof R, van Berge Henegouwen GP, et al. Temporal relationships between episodes of non-cardiac chest pain and abnormal oesophageal function. Gut 1994;35:733-6.

26 Shrestha S, Pasricha PJ. Update on noncardiac chest pain. Dig Dis 2000;18:138-46.
27 Adamek RJ, Wegener $M$, Wienbeck $M$, et al. Esophageal motility disorders and their coexistence with pathologic acid reflux in patients with noncardiac chest pain. Scand J Gastroenterol 1995;30:833-8.

28 Lacima G, Grande L, Pera M, et al. Utility of ambulatory 24-hour esophageal $\mathrm{pH}$ and motility monitoring in noncardiac chest pain: report of 90 patients and review of the literature. Dig Dis Sci 2003;48:952-61.

29 Cannon RO, Cattau EL, Yakshe PN, et al. Coronary flow reserve, esophageal motility, and chest pain in patients with angiographically normal coronary arteries. Am J Med 1990;88:217-22.

30 Xia HH, Lai KC, Lam SK, et al. Symptomatic response to lansoprazole predicts abnormal acid reflux in endoscopy-negative patients with non-cardiac chest pain. Aliment Pharmacol Ther 2003;17:369-77.

31 Nord HJ. Extraesophageal symptoms: what role for the proton pump inhibitors? Am J Med 2004;117(suppl 5A):56-62S.

32 Chey WD. Endoscopy-negative reflux disease: concepts and clinical practice. Am J Med 2004;117(suppl 5A):36-43S.

33 Kikendall JW, Mellow MH. Effect of sublingual nitroglycerin and long-acting nitrate preparations on esophageal motility. Gastroenterology 1980:79:703-6.

34 Cattau EL, Castell DO, Johnson DA, et al. Diltiazem therapy for symptoms associated with nutcracker esophagus. Am J Gastroenterol 1991;86:272-6.

35 Bortolotti M, Labriola E, Bacchelli S, et al. "Oesophageal angina" in patients with angina pectoris: a possible side effect of chronic therapy with nitrderivatives and Ca-antagonists. Ital J Gastroenterol 1992;24:405-8.

36 Katon W, Hall ML, Russo J, et al. Chest pain: relationship of psychiatric illness to coronary arteriographic results. Am J Med 1988;84:1-9.

37 Potts SG, Bass CM. Psychological morbidity in patients with chest pain and normal or near-normal coronary arteries: a long-term follow-up study. Psychol Med 1995:25:339-47.

38 Mayou RA, Bass CM, Bryant BM. Management of non-cardiac chest pain:from research to clinical practice. Heart 1999;81:387-92.

39 Prakash C, Clouse RE. Long-term outcome from tricyclic antidepressant treatment of functional chest pain. Dig Dis Sci 1999:44:2373-9.

40 Cannon RO, Quyyumi AA, Mincemoyer R, et al. Imipramine in patients with chest pain despite normal coronary angiograms. N Engl J Med 1994;330:1411-17

41 Clouse RE, Lustman PJ, Eckert TC, et al. Low-dose trazodone for symptomatic patients with esophageal contraction abnormalities. A double-blind, placebocontrolled trial. Gastroenterology 1987;92:1027-36.

42 Sarkar S, Thompson DG, Woolf CJ, et al. Patients with chest pain and occult gastroesophageal reflux demonstrate visceral pain hypersensitivity which may be partially responsive to acid suppression. Am J Gastroenterol 2004;99:1998-2006

43 Ilkjaer S, Dirks J, Brennum J, et al. Effect of systemic N-methyl-D-aspartate receptor antagonist (dextro methorphan) on primary and secondary hyperalgesia in humans. Br J Anaesth 1997;79:600-5.

44 Sarkar S, Hobson AR, Hughes A, et al. The prostaglandin E2 receptor-1 (EP-1) mediates acid-induced visceral pain hypersensitivity in humans. Gastroenterology 2003;124:18-25. 